\title{
OMERACT Definitions for Ultrasonographic Pathologies and Elementary Lesions of Rheumatic Disorders 15 Years On
}

\author{
George A. Bruyn, Annamaria Iagnocco, Esperanza Naredo, Peter V. Balint, Marwin Gutierrez, \\ Hilde B. Hammer, Paz Collado, Georgios Filippou, Wolfgang A. Schmidt, Sandrine Jousse-Joulin, \\ Peter Mandl, Philip G. Conaghan, Richard J. Wakefield (D), Helen I. Keen, Lene Terslev, \\ and Maria Antonietta D'Agostino, for the OMERACT Ultrasound Working Group
}

\begin{abstract}
Objective. The Outcome Measures in Rheumatology (OMERACT) Ultrasound (US) Working Group (WG) operates research activities for the validation of US as an outcome measurement instrument according to the Filter 2.0 framework.

Methods. Original publications on definitions and scoring systems for pathophysiological manifestations and elementary lesions of various rheumatic disorders were reviewed from the onset of the WG research in 2005.

Results. Definitions and scoring systems according to new terminology are provided.

Conclusion. We have redefined OMERACT US pathology and elementary lesions as well as scoring systems, which are now proposed for OMERACT approval for application in clinical trials. (First Release April 15 2019; J Rheumatol 2019;46:1388-93; doi:10.3899/jrheum.181095)

Key Indexing Terms:

$\begin{array}{lcc}\text { ULTRASOUND } & \text { IMAGING OUTCOME MEASUREMENT INSTRUMENT } \\ \text { OMERACT } & \text { SCORING SYSTEM }\end{array}$

OMERACT

SCORING SYSTEM

DEFINITIONS
\end{abstract}

From the Department of Rheumatology, MC Groep hospitals, Lelystad, the Netherlands; Academic Rheumatology Centre, Università degli Studi di Torino, Turin; Department of Medical Sciences, Section of Rheumatology, University of Ferrara; Azienda Ospedaliero-Universitaria Sant'Anna di Cona, Ferrara, Italy; Department of Rheumatology, Bone and Joint Research Unit, Hospital Universitario Fundación Jiménez Díaz, IIS Fundación Jiménez Díaz; Universidad Autónoma de Madrid; Rheumatology Department, Paediatric Rheumatology Unit, Hospital Universitario Severo Ochoa, Madrid, Spain; Rheumatology Department, National Institute of Rheumatology and Physiotherapy, Budapest, Hungary; Division of Musculoskeletal and Rheumatic Diseases, Instituto Nacional de Rehabilitacion, Mexico City, Mexico; Department of Rheumatology, Diakonhjemmet Hospital, Oslo, Norway; Immanuel Krankenhaus Berlin, Medical Center for Rheumatology Berlin-Buch, Berlin, Germany; Rheumatology Department, Cavale Blanche Hospital; Brest Occidentale University, Brest; Rheumatology Department, AP-HP, Hôpital Ambroise Paré, INSERM U1173, Labex Inflamex, Université Versailles St-Quentin en Yvelines, Boulogne-Billancourt, France; Department of Rheumatology, Medical University of Vienna, Vienna, Austria; Leeds Institute of Rheumatic and Musculoskeletal Medicine, University of Leeds; UK National Institute for Health Research (NIHR) Leeds Biomedical Research Centre, Leeds, UK; Department of Rheumatology, University of Adelaide, Adelaide, Australia; Copenhagen Center for Arthritis Research, Center for Rheumatology and Spine Diseases, Rigshospitalet, Copenhagen, Denmark.

PGC is funded in part by the NIHR Leeds Biomedical Research Centre. The views expressed are those of the authors and not necessarily those of the UK National Health Service, the NIHR, or the Department of Health. G.A.Bruyn, MD, PhD, Department of Rheumatology, MC Groep hospitals, Lelystad; A. Iagnocco, MD, Academic Rheumatology Centre, Università degli Studi di Torino; E. Naredo, MD, Department of Rheumatology, Bone and Joint Research Unit, and Hospital Universitario Fundación Jiménez. Díaz, IIS Fundación Jiménez Díaz, and Universidad Autónoma de Madrid; P.V. Balint, MD, PhD, Rheumatology Department, National Institute of Rheumatology and Physiotherapy; M. Gutierrez, MD, PhD, Division of Musculoskeletal and Rheumatic Diseases, Instituto Nacional de

\author{
Rehabilitacion; H.B. Hammer, MD, Department of Rheumatology, \\ Diakonhjemmet Hospital; P. Collado, MD, PhD, Rheumatology \\ Department, Paediatric Rheumatology Unit, Hospital Universitario \\ Severo Ochoa; G. Filippou, MD, PhD, Department of Medical Sciences, \\ Section of Rheumatology, University of Ferrara, and Azienda \\ Ospedaliero-Universitaria Sant'Anna di Cona; W.A. Schmidt, MD, \\ Immanuel Krankenhaus Berlin, Medical Center for Rheumatology Berlin- \\ Buch; S. Jousse-Joulin, MD, Rheumatology Department, Cavale Blanche \\ Hospital, and Brest Occidentale University; P. Mandl, PhD, Department \\ of Rheumatology, Medical University of Vienna; P.G. Conaghan, MD, \\ PhD, Leeds Institute of Rheumatic and Musculoskeletal Medicine, \\ University of Leeds, and NIHR Leeds Biomedical Research Centre; \\ R.J. Wakefield, MD, Leeds Institute of Rheumatic and Musculoskeletal \\ Medicine, University of Leeds, and NIHR Leeds Biomedical Research \\ Centre; H.I. Keen, MD, PhD, Department of Rheumatology, University of \\ Adelaide; L. Terslev, MD, PhD, Copenhagen Center for Arthritis \\ Research, Center for Rheumatology and Spine Diseases, Rigshospitalet; \\ M.A.D'Agostino, MD, PhD, Rheumatology Department, AP-HP, Hôpital \\ Ambroise Paré, INSERM U1173, Labex Inflamex, Université Versailles \\ St-Quentin en Yvelines. \\ Address correspondence to Prof. M.A. D'Agostino, Rheumatology \\ Department, Ambroise Paré Hospital, 9 avenue Charles de Gaulle, \\ 92100 Boulogne-Billancourt, France. \\ E-mail: maria-antonietta.dagostino@apr.aphp.fr \\ Accepted for publication January 18, 2019.
}

Since their introduction in $2005^{1}$, provisional ultrasound (US) definitions have become part of the fundamental Outcome Measures in Rheumatology (OMERACT) methodology for developing and validating US as a disease outcome measurement instrument (OMI) across various domains including inflammatory burden and structural damage ${ }^{2,3}$. 
In a seminal paper, the OMERACT Ultrasound (US) Working Group (WG) described 6 provisional definitions of US lesions considered to represent an "US core set" of pathophysiological manifestations in rheumatic diseases ${ }^{1}$. The definitions were truly provisional, as at that time, a concurrent systematic literature review (SLR) highlighted the lack of consensus-based definitions in the existing literature ${ }^{4}$.

Since then, iterative validation exercises have repeatedly shown US to be a reliable OMI for measuring (ir)reversible pathophysiological manifestations of rheumatoid arthritis (RA), i.e., synovitis, tenosynovitis ${ }^{5,6,7}$, or erosions. Further, the OMERACT US WG has engaged in the validation of US as an OMI by defining US manifestations of rheumatic disorders other than RA, including osteoarthritis, spondyloarthritis (SpA), psoriatic arthritis (PsA), crystal-related arthropathies, large vessel vasculitis, Sjögren syndrome, systemic lupus erythematosus (SLE), as well as in juvenile inflammatory arthritis. The validation process not only resulted in a refinement of the original US definitions for RA pathologies but also in defining new disease-associated pathologies and corresponding elementary lesions.

This report provides an overview of the WG activities and presents the new US definitions and scoring systems for synovitis, enthesitis, tenosynovitis, and tendon damage.

\section{Updated Definitions}

Synovitis. Rather than defining a single entity, the initial definition included 2 elementary lesions, synovial effusion, and synovial hypertrophy. Either one, separate or combined, could indicate synovitis ${ }^{1}$.

Following a stepwise validation process that consisted of a Delphi exercise for developing consensual definitions of pathology and elementary lesions, Web-based and patient reliability exercises testing systematically the validity and the reliability of those lesions ${ }^{6,7}$, a sub-task force of the OMERACT US WG concluded that the old definition of synovitis was not sustainable. The "new" definition of an US-detected synovitis encompasses the whole concept of synovitis, thereby delineating synovial hypertrophy $(\mathrm{SH})$ in a semiquantitative graded $\mathrm{B}$ mode feature and a graded Doppler mode feature. The presence of a hypoechoic SH is mandatory for defining the presence of an US-detected synovitis and for grading Doppler activity. Further, the new definition lacks the elementary lesion "synovial effusion," because it did not prove reliable and was frequently detected in healthy subjects $6,7,8$. In addition, the group developed a synovitis scoring system ${ }^{6,7}$ combining B mode and Doppler mode, which demonstrated sensitivity to change in small and large joints ${ }^{9}$. The new synovitis definition is presented in Table 1, and the new definition of the related elementary lesions is reported in Table 2. The combined European League Against Rheumatism (EULAR)-OMERACT scoring system is reported in the Supplementary Table 1 (available with the online version of this article).
Enthesitis. Whereas the provisional US definition spoke of enthesopathy ${ }^{1}$, this term is now singled out exclusively for a mechanically related enthesopathy including sports-related activities $^{10,11}$.

Based on an SLR, a high variability was found in the definition of enthesitis, and in particular its constituent elementary components, and no consensus-based scoring existed ${ }^{10}$. This inhomogeneity resulted in an appropriate task force to work on the development of a validated definition of enthesitis, using the same methodology described for developing synovitis ${ }^{11,12}$. The final definition of enthesitis is shown in Table 1 and can be used in SpA and PsA, along with the elementary lesions that should be detected for defining such a pathological entity (Table 2) and the scoring system to use for grading these elementary lesions ${ }^{12}$. The scoring of Doppler was further refined in a recent Delphi exercise (unpublished data) obtaining $>75 \%$ consensus on a semiquantitative scoring 0-3 (Supplementary Table 2, available with the online version of this article).

Tenosynovitis and tendon damage. Following the same systematic stepwise process, the OMERACT US WG conducted a series of formal Delphi studies and reliability exercises on elementary lesions of tenosynovitis and tendon damage, resulting in new definitions of tenosynovitis and related elementary lesions (Table 1 and Table 2), as well as 2 scoring systems, one for tenosynovitis and one for tendon damage (Supplementary Table 3, available with the online version of this article) ${ }^{13,14}$. Tendon damage is a structural lesion and solely defined in B mode, because this mode allows the evaluation of the morphology. Criterion validity of the tendon damage definition was demonstrated in cadavers ${ }^{15}$. The new definition of tenosynovitis includes changes in B mode and Doppler mode and has shown sensitivity to change in patients with RA ${ }^{16}$.

Bone erosion. The original OMERACT definition of bone erosion spoke of "an intraarticular discontinuity of the bone surface that is visible in two perpendicular planes" ${ }^{\text {. Because }}$ no new definition has been developed, this definition is still valid (Table 1) ${ }^{17}$. Future research will focus on distinguishing "true" RA erosions from other cortical breaks, e.g., vessel channels.

Osteoarthritis (OA). Initial activities on OA started as a joint venture between the OMERACT US WG and Osteoarthritis Research International and were mainly focused on structural abnormalities in hand OA. By testing the reliability of US in defining and grading cartilage lesions and osteophytes, the group produced a dichotomous and a 4-grade semiquantitative score for cartilage damage and osteophytes, respectively (Table 2; Supplementary Table 4, available with the online version of this article) ${ }^{18,19}$. Following the work on hand OA, the group targeted other joints ${ }^{20}$.

Juvenile idiopathic arthritis (JIA). Before defining synovitis in children, the JIA task force developed and validated defini-

Personal non-commercial use only. The Journal of Rheumatology Copyright @ 2019 . All rights reserved. 
Table 1. New OMERACT definitions of US-detected pathologies.

\begin{tabular}{ll}
\hline Type & Description \\
\hline Synovitis & $\begin{array}{l}\text { Presence of a hypoechoic synovial hypertrophy regardless of the presence of effusion } \\
\text { or any grade of Doppler signal. }\end{array}$ \\
Enthesitis & $\begin{array}{l}\text { Hypoechoic and/or thickened insertion of the enthesis close to the bone (within } \\
\text { shm from the bony cortex) which exhibits Doppler signal if active and that may } \\
\text { show erosions, enthesophytes/calcifications as sign of structural damage. }\end{array}$ \\
& $\begin{array}{l}\text { Abnormal anechoic and/or hypoechoic (relative to tendon fibers) tendon sheath } \\
\text { widening, which can be related both to the presence of tenosynovial abnormal fluid } \\
\text { and/or hypertrophy. Doppler signal can be considered if seen in } 2 \text { perpendicular } \\
\text { planes, within the peritendinous synovial sheath, excluding normal feeding vessels } \\
\text { (i.e., vessels at the mesotenon or vinculae or vessels entering the synovial sheath } \\
\text { from surrounding tissues). Doppler mode should be used only if the tendon shows } \\
\text { peritendinous synovial sheath widening on B mode. }\end{array}$ \\
Internal and/or peripheral focal tendon defect (i.e., absence of fibers) in the region \\
enclosed by tendon sheath, seen in 2 perpendicular planes; the grade of tendon \\
damage should be assessed in both planes.
\end{tabular}

OMERACT: Outcome Measures in Rheumatology; US: ultrasound.

tions of normal joint components for different age groups through a Delphi consensus process and by testing them in a reliability exercise involving healthy children ${ }^{21,22,23,24}$. In contrast to the definition of synovitis in adults, the US definition in children also includes synovial effusion ${ }^{25}$. The combined scoring system for synovitis using B mode and PD mode is presented in Supplementary Table 5 (available with the online version of this article).

Gout. Following an $\mathrm{SLR}^{26}$, the group conducted a Delphi exercise with the aim of obtaining and defining the elementary components of the gouty joint ${ }^{27}$. Four definitions of elementary lesions were highlighted, i.e., double contour, aggregates, tophus, and erosions (Table 1 and Table 2), and subsequently tested for reliability in a patient-based exercise ${ }^{28}$. Future work will determine whether these elementary lesions are reliable in the development of a scoring system.

Calcium pyrophosphate crystal deposit (CPPD) disease. Although no therapeutic drugs have been specifically developed for treating CPPD disease, the WG felt that CPPD-related arthritis may be a confounding pathological manifestation. Following the OMERACT methodology, definitions of the US characteristics of CPPD at the level of fibrocartilage of the knee menisci and wrist, hyaline cartilage, tendons, and synovial fluid of the knee were obtained (Table 2; Supplementary Table 6, available with the online version of this article $)^{29}$. Subsequently, a series of reliability exercises validated these elementary lesions ${ }^{30}$.

Large vessel vasculitis/giant cell arteritis (GCA). The US appearance of normal temporal and extracranial large arteries (e.g., axillary arteries) and of respective lesions in vasculitis was defined ${ }^{31}$ (Table 2; Supplementary Table 7, available with the online version of this article). As a result of the consensus exercises, the "halo sign" and the "compression sign" are regarded as the most important US abnormalities for $\mathrm{GCA}^{32}$.

\section{DISCUSSION}

US is a unique OMI for rheumatic disease processes because it is capable of identifying both the inflammatory state and the structural damage. Starting from the 2005 preliminary definitions, novel US definitions have been developed and validated by the WG. In accordance with the Filter 3.1, the validation process of an US definition follows a stringent, step-by-step road map beginning with an SLR following the OMERACT Framework Instrument Selection Algorithm recommendations. Next is a Delphi consensus process, and image- and patient-based reliability studies ${ }^{33}$. For proof, responsiveness studies of US definition of synovitis and tenosynovitis have been carried out $^{8,15}$. Along with progressive implementation of the OMI into clinical trials, patient feedback will enforce refinement of the application of US, which is in agreement with the current Filter 2.1.

The WG work is far from done. Goals now include validating US as an OMI for monitoring disease activity in Sjögren syndrome, musculoskeletal involvement of SLE, dactylitis in PsA (which remains one of the most challenging concepts to reliably identify by imaging), cartilage involvement in RA, and scleroderma. As for dactylitis, work continues on a definition of paratendinitis.

In addition to the development and validation of new US definitions of different pathologies, further research needs to delineate the (minimal) discriminatory threshold of these US pathologies. The first attempt will be to define the threshold of an active synovitis in RA. Another important future

Personal non-commercial use only. The Journal of Rheumatology Copyright $\subset$ $\subset$ 2019. All rights reserved 
Table 2. New definitions of the elementary lesions composing the US pathologies.

\begin{tabular}{|c|c|}
\hline Pathology & Inflammatory Elementary Lesion \\
\hline Synovitis & $\begin{array}{l}\text { Synovial hypertrophy is defined as the presence of abnormal } \\
\text { hypoechoic synovial tissue within the capsule that is not } \\
\text { displaceable and poorly compressible and that may exhibit } \\
\text { Doppler signals }\end{array}$ \\
\hline Enthesitis & $\begin{array}{l}\text { Hypoechoic increased thickness of anatomical enthesis (i.e., } \\
\text { tendon insertion }<2 \mathrm{~mm} \text { from the bony surface) that exhibits } \\
\text { Doppler signal }\end{array}$ \\
\hline Tenosynovitis & $\begin{array}{l}\text { Tenosynovial hypertrophy is defined as the presence of abnormal } \\
\text { hypoechoic (relative to tendon fibers) tissue within the synovial } \\
\text { sheath that is not displaceable and poorly compressible, and } \\
\text { seen in } 2 \text { perpendicular planes; it may exhibit Doppler signals }\end{array}$ \\
\hline
\end{tabular}

OA osteophytes

Step-up bony prominence at the bony margin that is visible in 2 perpendicular planes

OA hyaline cartilage damage

Loss of anechoic structure and/or thinning of cartilage layer, and irregularities and/or sharpness of at least 1 cartilage margin

Gout DC

Gout tophus

Gout aggregates

CPPD fibrocartilage

CPPD hyaline cartilage

CPPD tendon

CPPD synovial fluid

Halo sign

Homogeneous, hypoechoic wall thickening, well delineated

Abnormal hyperechoic band over the superficial margin of the articular hyaline cartilage, independent of the angle of insonation which may be either irregular or regular, continuous or intermittent and can be distinguished from the cartilage interface sign

Circumscribed, inhomogeneous, hyperechoic and/or hypoechoic aggregation (which may or may not generate posterior acoustic shadow), which may be surrounded by a small anechoic rim

Heterogeneous hyperechoic foci that maintain their high degree of reflectivity, even when the gain setting is minimized or the insonation angle is changed and which occasionally may generate posterior acoustic shadow

Hyperechoic deposits of variable shape, localized within the fibrocartilage structure, that remain fixed or move along with the fibrocartilage during dynamic assessment

Hyperechoic deposits of variable size and shape, without posterior shadowing, localized within the hyaline cartilage, that remain fixed and move along with the hyaline cartilage during dynamic assessment

Hyperechoic, linear structure(s) generally without posterior shadowing, localized within the tendon and remaining fixed and moving along with the tendon during dynamic assessment

Hyperechoic deposits of variable size, localized within the synovial fluid, without posterior shadowing, and mobile along with joint movement and probe pressure toward the luminal side, visible in 2 perpendicular planes, most commonly concentric in transverse scan

Compression sign Thickened arterial wall remains visible under compression, i.e., the echogenicity contrasts hypoechogenic because of vasculitic vessel wall thickening in comparison to mid/hyperechoic surrounding tissue

US: ultrasound; DC: double contour; OA: osteoarthritis; CPPD: calcium pyrophosphate deposit.

activity will be the development of a reduced joint count based on the existing EULAR-OMERACT scoring system.

We have redefined OMERACT definitions of US pathologies and elementary lesions. These updated definitions provided clarity as we completed the validation of these criteria and scoring systems, which are now proposed for approval for application in clinical trials .

\section{APPENDIX 1.}

List of study collaborators. The OMERACT Ultrasound Working Group: Sibel Aydin, Marina Backhaus, Artur Bachta, Isabelle Chary-Valckenaere, Stavros Chrysidis, Nemanja Damjanov, Bhaskar Dasgupta, Emilio Filippucci, Frederique Gandjbachkh, Andrew Filer, Stephanie Finzel, Petra Hanova, Alojzija Hocevar, Cristina Hernandez Diaz, Kei Ikeda, Nevsun Inanc, Gurjit Kaeley, Marion Kortekaas, Gavin Lee, Damien Loeuille, Silvia Magni Manzoni, Clara Malattia, Mihaela Micu, Ingrid Moller, Carlos

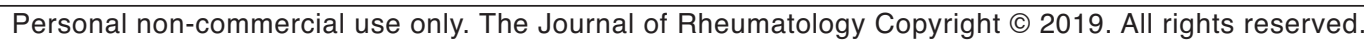


Pineda, Viviana Ravagnani, Bethan Richards, Johannes Roth, Valentin Schäfer, Andrea delle Sedie, Marcin Skzudlarek, Nicolas Tzaribachev, Ilfita Sahbudin, Maria Stoenoiu, Giorgio Tamborrini, Violeta Vlad, Jelena Vojinovic, Ken Warrington, Daniel Windschall, Priscilla Wong, and Pascal Zuferrey.

\section{ONLINE SUPPLEMENT}

Supplementary material accompanies the online version of this article.

\section{REFERENCES}

1. Wakefield RJ, Balint PV, Szkudlarek M, Filippucci E, Backhaus M, D'Agostino MA, et al; OMERACT 7 Special Interest Group. Musculoskeletal Ultrasound including definitions for ultrasonographic pathology. J Rheumatol 2005;32:2485-7.

2. Boers M, Kirwan JR, Tugwell P, Beaton D, Bingham CO III, Conaghan PG, et al. The OMERACT Handbook. [Internet. Accessed March 21, 2019.] Available from: https://omeract.org/resources

3. Boers M, Kirwan JR, Wells G, Beaton D, Gossec L, d'Agostino MA, et al. Developing core outcome measurement sets for clinical trials: OMERACT filter 2.0. J Clin Epidemiol 2014;67:745-53.

4. Joshua F, Lassere M, Bruyn GA, Szkudlarek M, Naredo E, Schmidt WA, et al. Summary findings of a systematic review of the ultrasound assessment of synovitis. J Rheumatol 2007;34:839-44.

5. Mandl P, Naredo E, Wakefield RJ, Conaghan PG, D'Agostino MA OMERACT Ultrasound Task Force. A systematic literature review analysis of ultrasound joint count and scoring systems to assess synovitis in rheumatoid arthritis according to the OMERACT filter. J Rheumatol 2011;38:2055-62.

6. D'Agostino MA, Terslev L, Aegerter P, Backhaus M, Balint P, Bruyn GA, et al. Scoring ultrasound synovitis in rheumatoid arthritis: a EULAR-OMERACT ultrasound taskforce-Part 1: definition and development of a standardised, consensus-based scoring system. RMD Open 2017;3:e000428.

7. Terslev L, Naredo E, Aegerter P, Wakefield RJ, Backhaus M, Balint $\mathrm{P}$, et al. Scoring ultrasound synovitis in rheumatoid arthritis: a EULAR-OMERACT ultrasound taskforce-Part 2: reliability and application to multiple joints of a standardised consensus-based scoring system. RMD Open 2017;3:e000427.

8. Padovano I, Costantino F, Breban M, D'Agostino MA. Prevalence of ultrasound synovial inflammatory findings in healthy subjects. Ann Rheum Dis 2016;75:1819-23.

9. D'Agostino MA, Boers M, Wakefield RJ, Hammer H, Vittecoq O, Filippou G, et al. Exploring a new ultrasound score as a clinical predictive tool in patients with rheumatoid arthritis starting abatacept: results from the APPRAISE study. RMD Open 2016;2:e000237.

10. Gandjbakhch F, Terslev L, Joshua F, Wakefield RJ, Naredo E, D'Agostino MA; OMERACT Ultrasound Task Force. Ultrasound in the evaluation of enthesitis: status and perspectives. Arthritis Res Ther 2011;13:R188.

11. Terslev L, Naredo E, Iagnocco A, Balint PV, Wakefield RJ, Aegerter $\mathrm{P}$, et al; Outcome Measures in Rheumatology Ultrasound Task Force. Defining enthesitis in spondyloarthritis by ultrasound: results of a Delphi process and of a reliability reading exercise. Arthritis Care Res 2014;66:741-8.

12. Balint PV, Terslev L, Aegerter P, Bruyn GA, Chary-Valckenaere I, Gandjbakhch F, et al; OMERACT Ultrasound Task Force members. Reliability of a consensus-based ultrasound definition and scoring for enthesitis in spondyloarthritis and psoriatic arthritis: an OMERACT US initiative. Ann Rheum Dis 2018;77:1730-5.

13. Naredo E, D'Agostino MA, Wakefield RJ, Möller I, Balint PV, Filippucci E, et al; OMERACT Ultrasound Task Force. Reliability of a consensus-based ultrasound score for tenosynovitis in rheumatoid arthritis. Ann Rheum Dis 2013;72:1328-34

14. Bruyn GA, Hanova P, Iagnocco A, D'Agostino MA, Möller I, Terslev L, al; OMERACT Ultrasound Task Force. Ultrasound definition of tendon damage in patients with rheumatoid arthritis. Results of a OMERACT consensus-based ultrasound score focussing on the diagnostic reliability. Ann Rheum Dis 2014;73:1929-34.

15. Janta I, Morán J, Naredo E, Nieto JC, Uson J, Möller I, et al. How does a cadaver model work for testing ultrasound diagnostic capability for rheumatic-like tendon damage? Rheumatol Int 2016;36:863-9.

16. Ammitzbøll-Danielsen M, Østergaard M, Naredo E, Terslev L Validity and sensitivity to change of the semi-quantitative OMERACT ultrasound scoring system for tenosynovitis in patients with rheumatoid arthritis. Rheumatology 2016;55:2156-66.

17. Szkudlarek M, Terslev L, Wakefield RJ, Backhaus M, Balint PV, Bruyn GA, et al. Summary findings of a systematic literature review of the ultrasound assessment of bone erosions in rheumatoid arthritis. J Rheumatol 2016;43;12-21.

18. Hammer HB, Iagnocco A, Mathiessen A, Filippucci E, Gandjbakhch F, Kortekaas MC, et al. Global ultrasound assessment of structural lesions in osteoarthritis: a reliability study by the OMERACT ultrasonography group on scoring cartilage and osteophytes in finger joints. Ann Rheum Dis 2016;75:402-7.

19. Iagnocco A, Conaghan PG, Aegerter P, Möller I, Bruyn GA, Chary-Valckenaere I, et al. The reliability of musculoskeleta ultrasound in the detection of cartilage abnormalities at the metacarpo-phalangeal joints. Osteoarthritis Cartilage 2012; 20:1142-6.

20. Bruyn GA, Naredo E, Damjanov N, Bachta A, Baudoin P, Hammer $\mathrm{HB}$, et al; Ultrasound Task Force. An OMERACT reliability exercise of inflammatory and structural abnormalities in patients with knee osteoarthritis using ultrasound assessment. Ann Rheumatic Dis 2016;75:842-6.

21. Roth J, Jousse-Joulin S, Magni-Manzoni S, Rodriguez A, Tzaribachev N, Iagnocco A, et al; Outcome Measures in Rheumatology Ultrasound Group. Definitions for the sonographic features of joints in healthy children. Arthritis Care Res 2015;67:136-42.

22. Collado P, Windschall D, Vojinovic J, Magni-Manzoni S, Balint P, Bruyn GAW, et al; OMERACT ultrasound subtask force on pediatric. Amendment of the OMERACT ultrasound definitions of joints' features in healthy children when using the DOPPLER technique. Pediatr Rheumatol Online J 2018;16:23

23. Windschall D, Collado P, Vojinovic J, Magni-Manzoni S, Balint P, Bruyn GAW, et al; OMERACT paediatric ultrasound subtask force. Age-related vascularization and ossification in joints in children: an international pilot study to test the multi-observer ultrasound reliability. Arthritis Care Res 2017 Aug 4 (E-pub ahead of print).

24. Collado P, Vojinovic J, Nieto JC, Windschall D, Magni-Manzoni S, Bruyn GA, et al; OMERACT Ultrasound Pediatric Group. Toward standardized musculoskeletal ultrasound in pediatric rheumatology: normal age-related ultrasound findings. Arthritis Care Res 2016;68:348-56

25. Roth J, Ravignani V, Backhaus M, Balint P, Bruns A, Bruyn GA, et al; OMERACT Ultrasound Group. Preliminary definitions for the sonographic features of synovitis in children. Arthritis Care Res 2017;69:1217-23.

26. Chowalloor PV, Keen HI. A systematic review of ultrasonography in gout and asymptomatic hyperuricaemia. Ann Rheum Dis 2013;72:638-45.

27. Gutierrez M, Schmidt WA, Thiele R, Keen H, Kaeley G, Naredo E, et al; OMERACT Ultrasound Gout Task Force group. International consensus for ultrasound lesions in gout: results of Delphi process and web-reliability exercise. Rheumatology 2015;54:1797-805. 
28. Terslev L, Gutierrez M, Christensen R, Balint PV, Bruyn GA, Delle Sedie A, et al; OMERACT US Gout Task Force. Assessing elementary lesions in gout by ultrasound: results of an OMERACT patient-based agreement and reliability exercise. J Rheumatol 2015;42:2149-54.

29. Filippou G, Scirè CA, Damjanov N, Adinolfi A, Carrara G, Picerno $\mathrm{V}$, et al. Definition and reliability assessment of elementary ultrasonographic findings in calcium pyrophosphate deposition disease: a study by the OMERACT calcium pyrophosphate deposition disease ultrasound subtask force. J Rheumatol 2017;44:1744-9.

30. Filippou G, Scirè CA, Adinolfi A, Damjanov N, Carrara G, Bruyn $\mathrm{GAW}$, et al. Identification of calcium pyrophosphate deposition disease (CPPD) by ultrasound: reliability of the OMERACT definitions in an extended set of joints-an international multiobserver study by the OMERACT calcium pyrophosphate deposition disease ultrasound subtask force. Ann Rheumatic Dis 2018;77:1194-8.
31. Chrysidis S, Duftner C, Dejaco C, Schäfer VS, Ramiro S, Carrara $\mathrm{G}$, et al. Definitions and reliability assessment of elementary ultrasound lesions in giant cell arteritis: a study from the OMERACT large vessel vasculitis ultrasound working group. RMD Open 2018;4:e000598.

32. Schäfer VS, Chrysidis S, Dejaco C, Duftner C, Iagnocco A, Bruyn GA, et al. Assessing vasculitis in giant cell arteritis by ultrasound: results of OMERACT patient-based reliability exercises. J Rheumatol 2018;45:1289-95.

33. Terslev L, Naredo E, Keen HI, Bruyn GA, Iagnocco A, Wakefield RJ, et al. The OMERACT stepwise approach to select and develop imaging outcome measurement instruments: the musculoskeletal ultrasound example. J Rheumatol 2019;46:1394-1400. 